\title{
Wear behavior and microhardness of some W/Cu functionally graded materials obtained by spark plasma sintering
}

\author{
Claudiu NICOLICESCU ${ }^{1, a^{*}}$, Victor Horia NICOARA ${ }^{2, b}$, Florin POPA ${ }^{3, c}$, Traian \\ Florin MARINCA ${ }^{4, d}$ \\ ${ }^{1,2}$ University of Craiova, Faculty of Mechanics, Department of Engineering and Management of \\ the Technological Systems, Drobeta-Turnu Severin, Romania \\ ${ }^{3,4}$ Technical University of Cluj-Napoca, Faculty of Materials and Environmental Engineering, \\ Department of Materials Science and Engineering, Technical University of Cluj-Napoca, Cluj- \\ Napoca, Romania \\ anicolicescu_claudiu@yahoo.com, ${ }^{b}$ victorczh@gmail.com, ${ }^{c}$ florin.popa@stm.utcluj.ro, \\ dtraian.marinca@stm.utcluj.ro
}

Keywords: Functionally graded materials, Spark plasma sintering, Wear rate, Friction coefficient, Microhardness, Scanning electron microscopy, Optical microscopy

\begin{abstract}
This paper is focused on the elaboration of some $\mathrm{W} / \mathrm{Cu}$ functionally graded materials (FGM) by spark plasma sintering (SPS) process, as well as on their characterization, from the wear behavior and microhardness point of view function of composition and sintering temperature. The raw materials used for the research were $\mathrm{W} / \mathrm{Cu}$ mechanically alloyed powders for 20 hours, which were subjected to consolidation in three layers of compositions $\mathrm{W}_{100-\mathrm{x}} \mathrm{Cu}_{\mathrm{x}}$, where $\mathrm{x}$ is 25,30 and $40 \% \mathrm{wt}$. by SPS. The evolution of tribological parameters and microhardness function of the chemical composition and SPS temperature were investigated. Microhardness is influenced by the SPS temperature and composition of the layers namely, the highest value was attained for the sample sintered at $950{ }^{\circ} \mathrm{C}$ and layer 1 which consists in $\mathrm{W}_{75} \mathrm{Cu}_{25}$. The wear behavior is influenced by the composition of the layers and by ball testing material (100Cr6 and alumina).
\end{abstract}

\section{Introduction}

Copper alloys are frequently used in applications that require high electrical and thermal conductivity. In some applications that require strength and wear resistance it is necessary to alloy copper with others metals. Alloys based on copper and tungsten attract the attention due to the combination of properties such as low thermal expansion coefficient, high melting point, high strength and wear resistance conferred by tungsten with a high electrical and thermal characteristics conferred by copper [1-6].

The researches in the field of $\mathrm{W} / \mathrm{Cu}$ alloys are focused on the controlling the microstructure by optimizing the composition or processing techniques [7-11]. Due to their insolubility and high differences between densities and melting points it's very difficult to produce $\mathrm{W} / \mathrm{Cu}$ composite. There are different methods to produce $\mathrm{W} / \mathrm{Cu}$ composite/nanocomposite namely: copper infiltration and liquid phase sintering $[10,12]$ which are considered classical methods, respectively new methods as mechanical alloying (MA), mechano-chemical processes (MCP) [13], mechanothermochemical processing (MTP) [14], the thermo-mechanical method [15], wet-chemical methods [16] and spray drying [17].

Functional graded materials (FGM) based on W/Cu represent a new category of materials consisting in two or more layers, in which the microstructure and the composition vary from the 
top layer to the bottom layer and vice versa. This class of materials presents some advantages comparative to the single layer materials, namely: the properties are different in each layer, residual and thermal stresses are reduced and the fracture strength is optimized [18-20]. The main fields of applications of W/Cu FGM are: electrical contacts, plasma facing materials, heat sink materials, etc. [21]

In recent decades, Spark Plasma Sintering (SPS) became a popular sintering method which is widely used in fabrication process of different materials as: ceramics, cermets, metals, hard materials, composite materials and FGMs [22-31]. The SPS process is different by conventional sintering in that, the cold pre-pressed powder is sintered by discharge impact, spark plasma, Joule heat and intrinsic field effects produced by additional strong pulse currents through the powders. The SPS is assisted by a vertical uniaxial load in order to accelerate the process. The main advantages of the SPS process are: rapid heating (over $200{ }^{\circ} \mathrm{C} / \mathrm{min}$ ), short dwell times, lower temperatures and fine microstructures [32, 33].

The present work is focused on the elaboration of three layers W/Cu FGM by SPS process. The composition of the layers consisting in $\mathrm{W}_{100-\mathrm{x}} \mathrm{Cu}_{\mathrm{x}}$, where $\mathrm{x}$ is 25,30 and $40 \%$ weight. The influence of the SPS temperature and layers composition on the wear behavior and microhardness were studied.

\section{Experimental work}

\section{Raw materials}

Tungsten nanopowders (Fig. 1a) obtained by mechanical milling for 35 hours with particle size about $50 \mathrm{~nm}$ (according to Dynamic Laser Scattering analysis) and copper micrometric powders

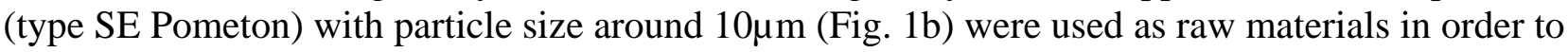
prepare the mixtures.
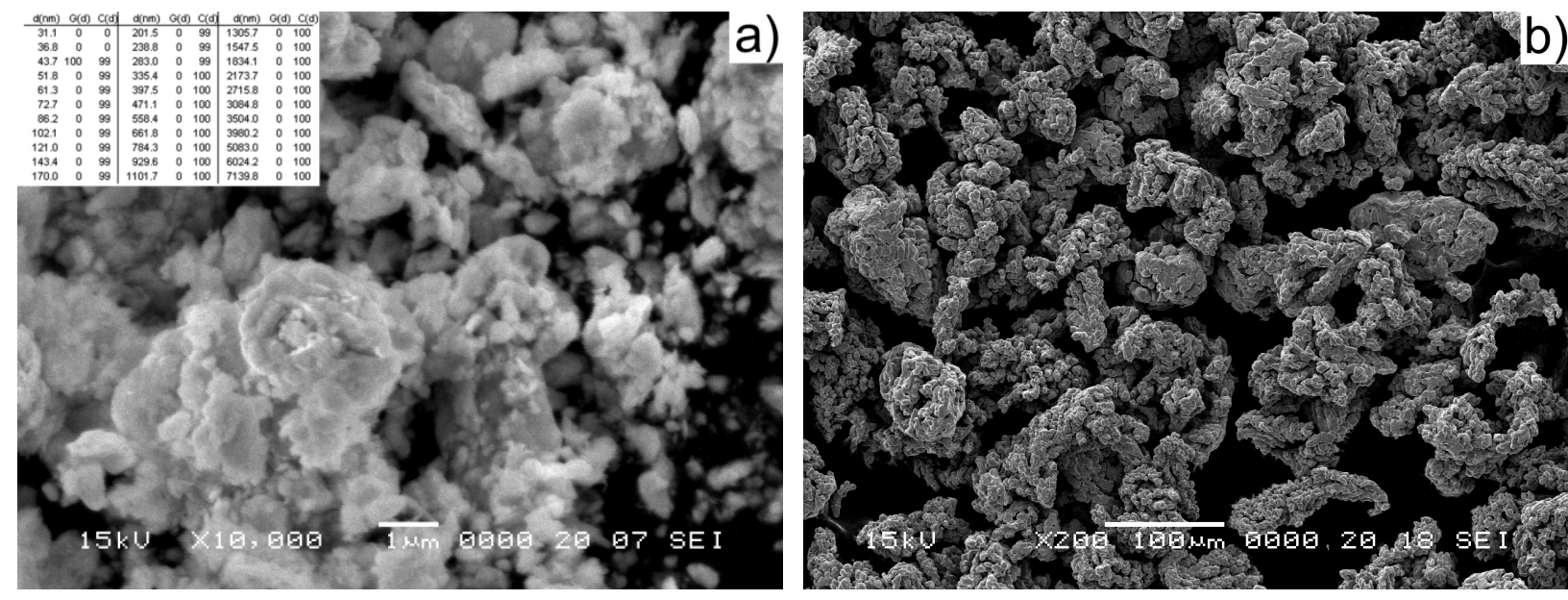

Fig. 1. SEM images of the starting powders: a) tungsten nanopowders; b) copper powders

Tungsten nanopowders are agglomerated and have irregular shape (Fig. 1a) comparative with copper powders (Fig. 1b) which have dendritic shape, corresponding to electrolytic process.

Three types of mixtures with the following concentrations (\% weight): $75 \mathrm{~W} / 25 \mathrm{Cu}, 70 \mathrm{~W} / 30 \mathrm{Cu}$ and $60 \mathrm{~W} / 40 \mathrm{Cu}$ were subjected to mechanical milling process for 20 hours in order to obtain composite powder. For mechanical milling (MM) process planetary ball mill Pulverisette 4 made by Fritsch was used. The milling parameters were: material of vials: stainless steel, vials volume: $250 \mathrm{ml}$, materials of balls: stainless steels, balls diameter: $\Phi=10 \mathrm{~mm}$, balls to powder ratio: $2 / 1$, 
rotational speed of the main disk: $400 \mathrm{rpm}$, rotational speeds of the vials: $-800 \mathrm{rpm}$, milling medium: argon, milling type: dry.

The SEM images and element distribution maps obtained by EDX analysis show that inside of particles of all mixtures, the component elements are homogenous dispersed (Fig. 2).
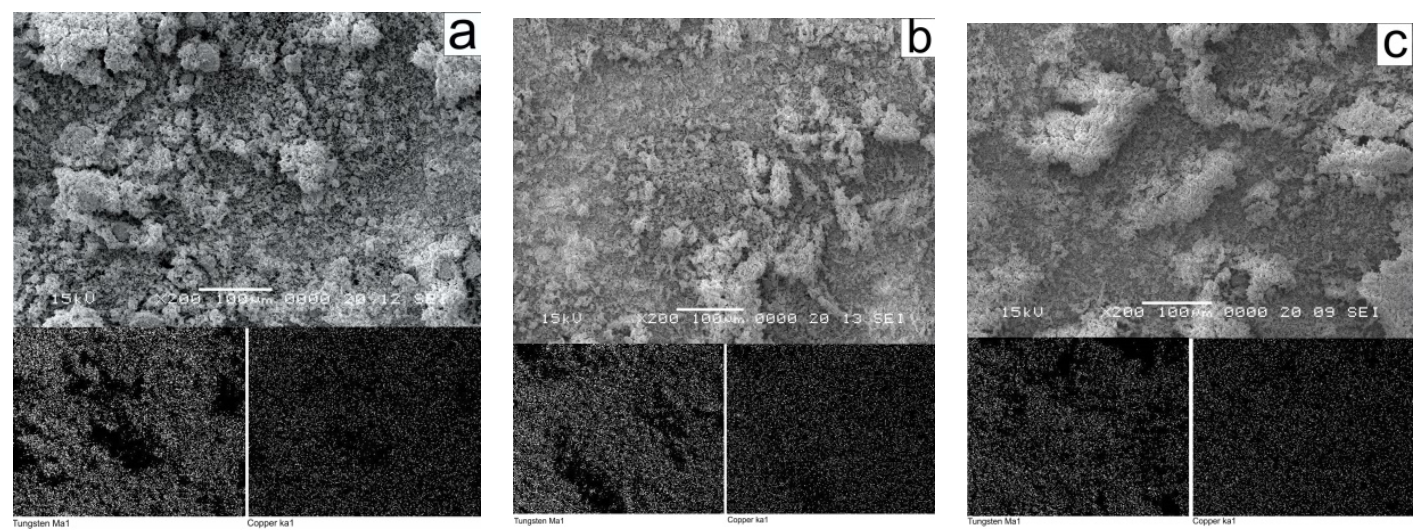

Fig. 2. SEM images and EDX analysis of the mixtures used for the research: a) $75 \mathrm{~W} / \mathrm{Cu}$; b) $70 \mathrm{~W} / \mathrm{Cu}$; c) $60 \mathrm{~W} / \mathrm{Cu}$

\section{Elaboration of functional graded materials}

The mixtures obtained after MM process was used in order to obtain three layered functional graded materials (FGM) by spark plasma sintering (SPS) according to the flow chart presented in (Fig. 3).

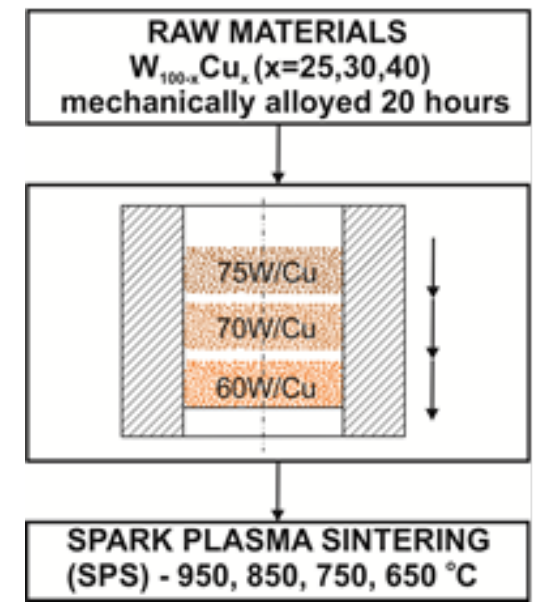

Fig. 3. Experimental flow chart

A thin graphite paper was put into the inner part of the die for lubrication and other two papers were put on the bottom and upper of the part in order to prevent the powder to stick on the graphite punches. The samples were sintered at four temperatures $\left(950,850,750\right.$ and $650{ }^{\circ} \mathrm{C}$ ) without dwell time and a pressure equal to $20 \mathrm{MPa}$ using a SPS homemade system from Technical University of Cluj-Napoca. The heating rate was about $300{ }^{\circ} \mathrm{C} / \mathrm{min}$. After SPS the density of the samples was measured by the Archimedes' method. The samples were cut and polished in order to study the microstructural aspects and microhardness. The optical microscopy was made using an NIKON microscope with NIS ELEMENTS image software. SEM characterisation was performed using a JEOL JSM5600LV microscope equipped with EDX spectrometer (Oxford Instruments, INCA 200 software). The micro hardness was measured using a Namicon tester with a load of 9.8 
$\mathrm{N}$ and a dwell time of 15 seconds. The investigation of wear behavior was performed using a CSM Instruments tribometer TRB 01-2541 and a Taylor Hobson Surtronic 25+ profilometer. The parameters for wear testing were: type: ball on disk; load $-2 \mathrm{~N}$; testing method - linear; amplitude - $6 \mathrm{~mm}$; speed - $10 \mathrm{~cm} / \mathrm{s}$; distance - $60 \mathrm{~m}$; ball material $-100 \mathrm{Cr} 6$ and alumina; temperature $-25^{\circ} \mathrm{C}$.

\section{Results and discussion}

The relative density function of the SPS temperature is plotted in (Fig. 4).

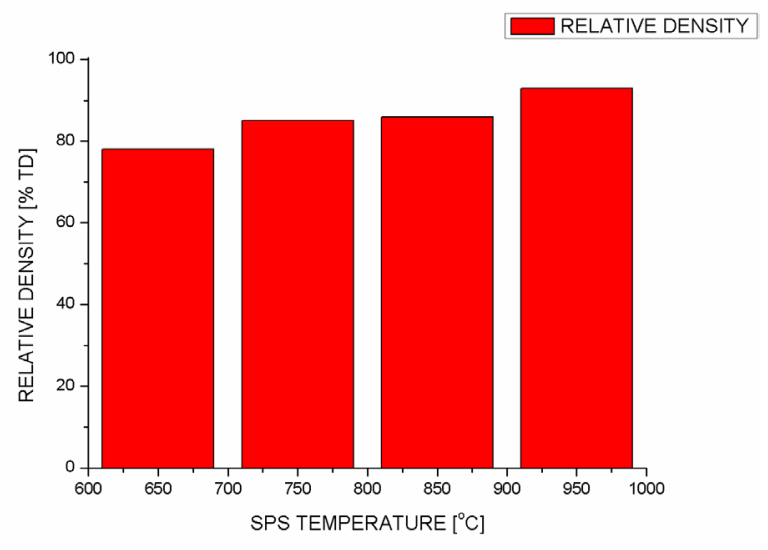

Fig. 4. Relative density function of the SPS temperature

The highest value of the density is attained at $950{ }^{\circ} \mathrm{C}$ and it is observed that it decrease with the decreasing of the sintering temperature.

Fig. 5 presents optical microscopy images of the samples (not etched) at the four sintering temperatures. The microstructures of the samples are homogenous and present structural gradient. The dark grey colour corresponds to the layer 1 with $75 \% \mathrm{~W}$ and so on. The thickness of the middle layer increases with the decreasing of the SPS temperature. The lowest value of the thickness $(1216.85 \mu \mathrm{m})$ was attained for the sample sintered at highest temperature $950{ }^{\circ} \mathrm{C}$. Higher density lead to lower thickness as expected.
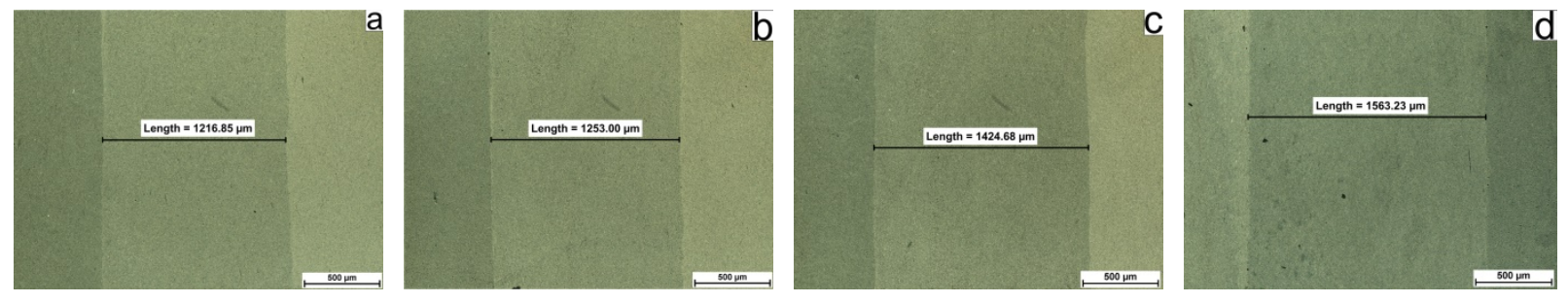

Fig. 5. Optical microscopy aspects of the three layered samples (75X): a) $950{ }^{\circ} \mathrm{C}$; b) $850{ }^{\circ} \mathrm{C}$; c)

$$
750{ }^{\circ} \mathrm{C} \text {; d) } 650{ }^{\circ} \mathrm{C}
$$

The EDX line distribution on the three layers, (Fig. 6) shows the distribution of $\mathrm{W}$ and copper function the scanning distance. It is observed that the content of $\mathrm{W}$ decrease from left (first layer $75 \% \mathrm{~W}$ ) to the right (third layer $-60 \% \mathrm{~W}$ ). In the same time a slight increase in $\mathrm{Cu}$ is recorded, according the layer composition change. In (Fig. 7) are presented the interfaces of the three layers. Analysing (Fig. 6, 7) it is obvious that the graded structure was attained. The interfaces seems to assure continuity from one layer to another as it can be seen in (Fig. 7). The composition 
differences between the layers are small, probably due to the powder superficial mix at the interface. In (Fig. 8) is plotted the evolution of the microhardness.
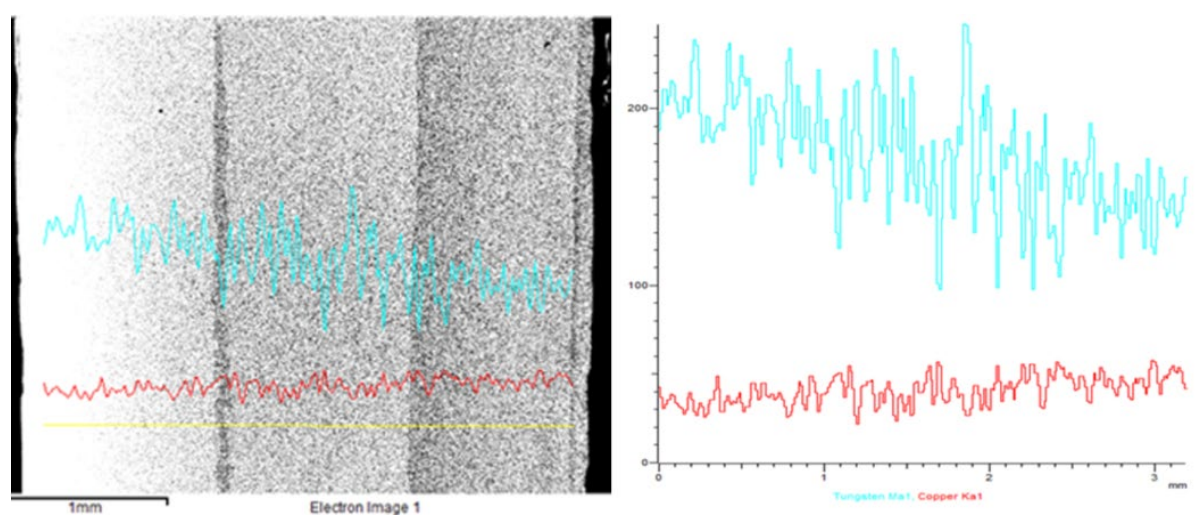

Fig. 6. SEM image (left) and EDX line distribution of $\mathrm{W}$ and $\mathrm{Cu}$ elements of the three layered W/Cu FGM obtained by SPS at $950{ }^{\circ} \mathrm{C}$
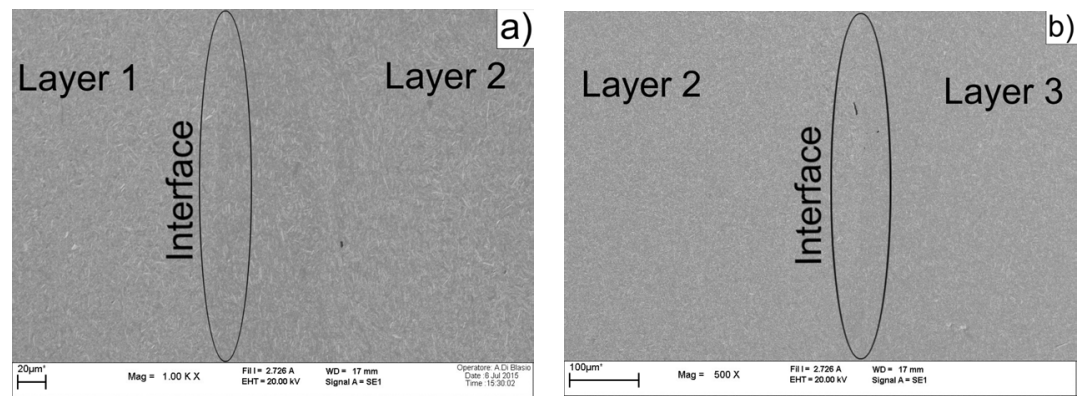

Fig. 7. SEM images of the interfaces of W/Cu FGM obtained by SPS at $950{ }^{\circ} \mathrm{C}$ : a) between layer 1 and layer 2; b) between layer 2 and layer 3 .

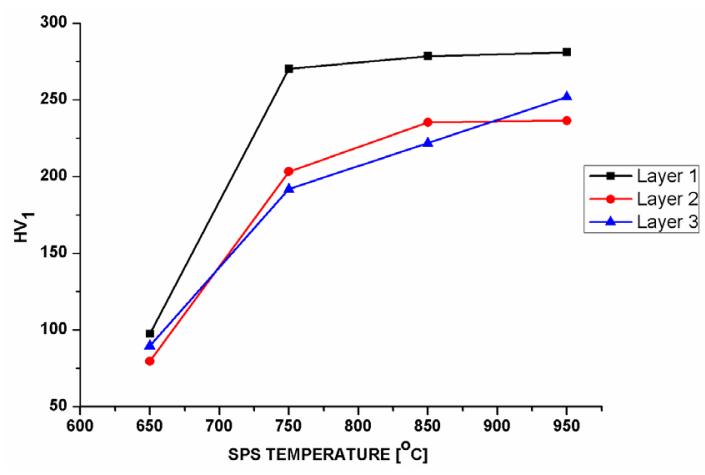

Fig. 8. Evolution of microhardness as a function of sintering temperature

The measurements of the microhardness were performed in all the three layers, even if only the layer 1 and 3 are important from this point of view, because only these are in contact with other materials. The bonding between $\mathrm{W}$ and copper particles influences the microhardness of the layers. The highest value of the microhardness was attained in the layer $1(75 \mathrm{~W} / \mathrm{Cu})$ sintered at $950{ }^{\circ} \mathrm{C}$ and it decreases with the decreasing of the $\mathrm{W}$ content. 
The results on the wear tests are presented in (Table 1) and the optical light microscopy of the worns resulted after the tribological tests (with 100Cr6 ball) are presented in (Fig. 9 and 10). In (Fig. 11) are presented optical images of the two balls after tribological tests.

Table 1. Wear test results

\begin{tabular}{|c|c|c|c|c|c|c|c|c|c|c|c|}
\hline \multirow{3}{*}{$\mathrm{T}\left[{ }^{\circ} \mathrm{C}\right]$} & \multirow{3}{*}{ Layer } & \multirow{2}{*}{\multicolumn{2}{|c|}{$\begin{array}{c}\begin{array}{c}\text { Mean friction } \\
\text { coefficient } \mu\end{array} \\
\text { Ball material }\end{array}$}} & \multirow{2}{*}{\multicolumn{2}{|c|}{$\begin{array}{c}\text { Worn track } \\
\text { section }\left[\mu \mathrm{m}^{2}\right] \\
\text { Ball material }\end{array}$}} & \multirow{2}{*}{\multicolumn{2}{|c|}{$\begin{array}{c}\text { Worn cap } \\
\text { diameter }[\mu \mathrm{m}] \\
\text { Ball material }\end{array}$}} & \multirow{2}{*}{\multicolumn{2}{|c|}{ 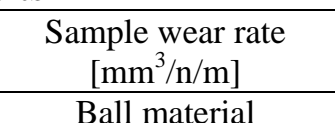 }} & \multicolumn{2}{|c|}{$\begin{array}{c}\text { Partner wear rate } \\
{\left[\mathrm{mm}^{3} / \mathrm{n} / \mathrm{m}\right]}\end{array}$} \\
\hline & & & & & & & & & & Ball ma & terial \\
\hline & & 100Cr6 & Alumina & $100 \mathrm{Cr} 6$ & Alumina & $100 \mathrm{Cr} 6$ & Alumina & 100Cr6 & Alumina & 100Cr6 & Alumina \\
\hline \multirow{2}{*}{950} & Layer 1 & 0.463 & 0.311 & 2735 & 88 & 459.7 & - & $136.7 * 10^{-6}$ & $4.4 * 10^{-6}$ & $6.101 * 10^{-6}$ & - \\
\hline & Layer 3 & 0.430 & 0.275 & 936.5 & 31.4 & 392.3 & - & $46.82 * 10^{-6}$ & $1.57 * 10^{-6}$ & $3.233 * 10^{-6}$ & - \\
\hline \multirow{2}{*}{850} & Layer 1 & 0.370 & 0.268 & 2153.5 & 74.5 & 446.3 & - & $107.7 * 10^{-6}$ & $3.727 * 10^{-6}$ & $5.421 * 10^{-6}$ & - \\
\hline & Layer 3 & 0.498 & 0.285 & 2426 & 50.6 & 473.3 & - & $121.3 * 10^{-6}$ & $2.528 * 10^{-6}$ & $6.858 * 10^{-6}$ & - \\
\hline \multirow{2}{*}{750} & Layer 1 & 0.423 & 0.295 & 2090 & 29.6 & 473.8 & - & $104.5 * 10^{-6}$ & $1.48 * 10^{-6}$ & $6.889 * 10^{-6}$ & - \\
\hline & Layer 3 & 0.461 & 0.287 & 457 & 59.1 & 151.4 & - & $22.85 * 10^{-6}$ & $2.955 * 10^{-6}$ & $7.158 * 10^{-8}$ & - \\
\hline \multirow{2}{*}{650} & Layer 1 & 0.472 & 0.342 & 91.5 & 641 & 271.3 & - & $4.572 * 10^{-6}$ & $32.05 * 10^{-6}$ & $7.393 * 10^{-7}$ & - \\
\hline & Layer 3 & 0.485 & 0.313 & 240.5 & 108.8 & 221.2 & - & $12.03 * 10^{-6}$ & $5.438 * 10^{-6}$ & $3.268 * 10^{-7}$ & - \\
\hline
\end{tabular}

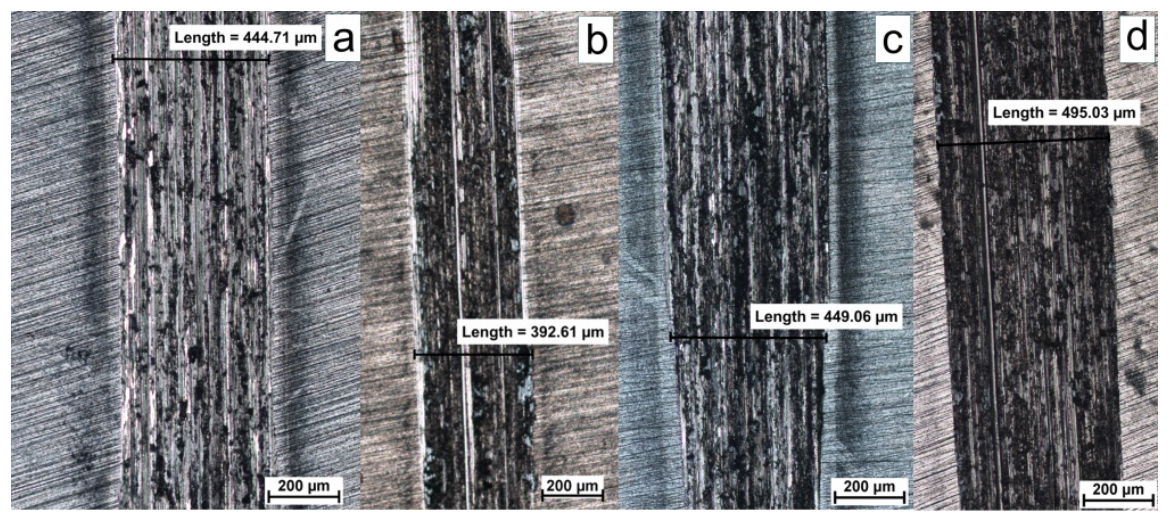

Fig. 9. Worn of the samples (75x): a) $950{ }^{\circ} \mathrm{C}$ layer 1; b) $950{ }^{\circ} \mathrm{C}$ layer 3; c) $850{ }^{\circ} \mathrm{C}$ layer 1 ; d) 850 ${ }^{\circ} \mathrm{C}$ layer 3

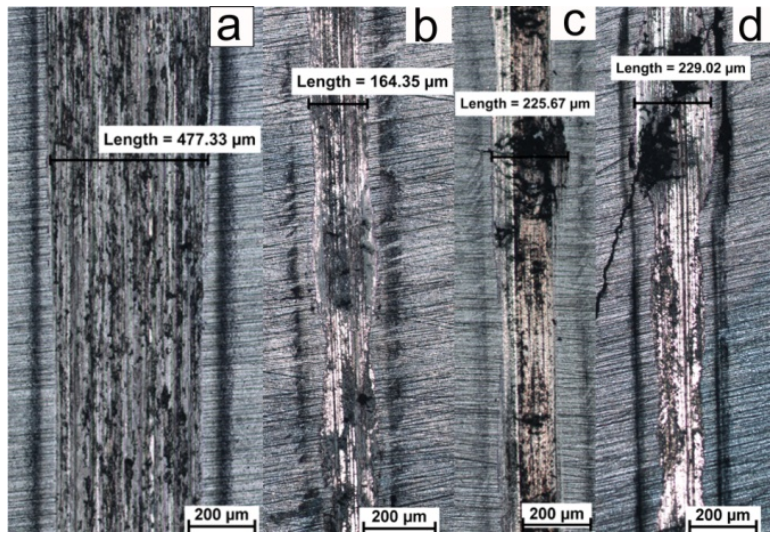

Fig. 10. Worn of the samples (75x): a) $750{ }^{\circ} \mathrm{C}$ layer 1 ; b) $750{ }^{\circ} \mathrm{C}$ layer 3; c) $650{ }^{\circ} \mathrm{C}$ layer 1 ; d) 650 ${ }^{\circ} \mathrm{C}$ layer 3

The tribological measurements were made only in the layer 1 and layer 3 because the material obtained is used for the fabrication of electrical contacts so, the middle layer is important only from the electrical and thermal point of view. The friction coefficient presents values in the range 
of $0.370-0.498$ for the samples which were tested with 100Cr6 ball which are higher than the friction coefficients obtain in the case of alumina ball (0.268-0.342). These values are lower compared with the case of $\mathrm{W}-30 \mathrm{wt} \% \mathrm{Cu}$ which reported friction coefficient about $\mu=0.64$ [34] respectively $\mu=0.78$ and $\mu=0.56$ in the case of $\mathrm{W}-25 \mathrm{wt} \% \mathrm{Cu}$ [35]. As it can be seen from (Fig. 11), the worn cap of the 100Cr6 ball is larger compared with that of the alumina ball in all the cases.
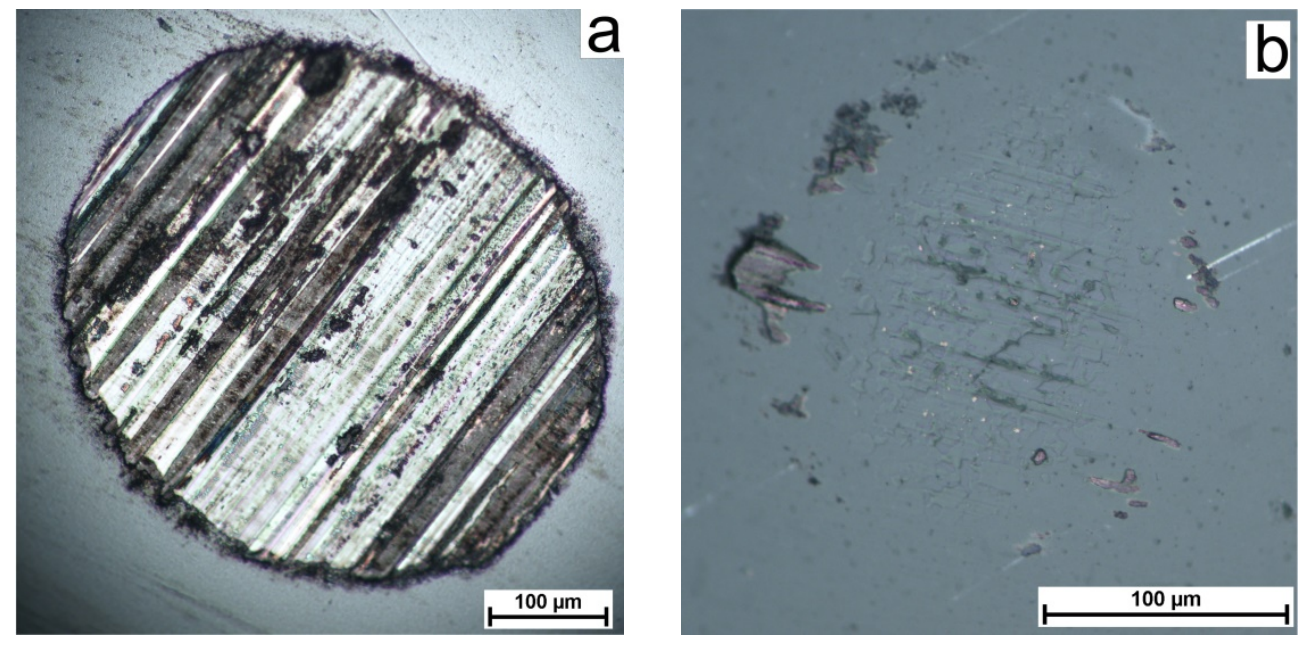

Fig. 11. Worn cap images of the balls after the test for the sample sintered at $950{ }^{\circ} \mathrm{C}$, layer 1: a) 100Cr6 ball (150X); b) alumina ball (300X)

From (Fig. 9, 10) it can be observed that the wear is abrasive due to the presence of the ball material on the sample. The worns of the samples are in accordance with the partner worns (balls). The samples sintered at $650{ }^{\circ} \mathrm{C}$ present micro cracks after the wear testing (Fig. 10 c, d)

\section{Summary}

The experimental results obtained in this research lead to the following conclusions:

- it can be obtained materials with functional and structural gradient by stacking layers and using spark plasma sintering;

- the microhardness is influenced by the sintering temperature and composition of the layers namely, it increasing with the increasing of W content and SPS temperature;

- regarding the tribological tests, in the case of sintered materials because the presence of the pores which tend to fill with material of the ball, the wear rates aren 't in accordance with the microhardness. Because of that, the sample sintered at $650{ }^{\circ} \mathrm{C}$ presents the lowest values for the worn track sections and wear rates.

\section{Acknowledgement}

This work was supported by the strategic grant POSDRU/159/1.5/S/133255, Project ID 133255 (2014), co-financed by the European Social Fund within the Sectorial Operational Program Human Resources Development 2007 - 2013

\section{References}

[1] K. Lu, The future of metals, Science, $328 \quad$ (2010) 319-320. https://doi.org/10.1126/science.1185866 
[2] C.F. Zhu, F.P. Du, Q.Y. Jiao, et al., Microstructure and strength of pure $\mathrm{Cu}$ with large grains processed by equal channel angular pressing, Mater. Des. 52 (2013) 23-29. https://doi.org/10.1016/j.matdes.2013.05.029

[3] K. Maki, Y. Ito, H. Matsunaga, H. Mori, Solid-solution copper alloys with high strength and high electrical conductivity, Scripta Mater. 68 (2013) 777-780. https://doi.org/10.1016/j.scriptamat.2012.12.027

[4] D.H. Dai, D.D. Gu, Thermal behavior and densification mechanism during selective laser melting of copper matrix composites: simulation and experiments, Mater. Des. 55 (2014) 482-491. https://doi.org/10.1016/j.matdes.2013.10.006

[5] B.B. Liu, J.X. Xie, X.H. Qu, Fabrication of W-Cu functionally graded materials with high density by particle size adjustment and solid state hot press, Compos. Sci. Technol. 68 (2008) 1539-1547. https://doi.org/10.1016/j.compscitech.2007.10.023

[6] N. Selvakumar, S.C. Vettivel, Thermal, electrical and wear behavior of sintered $\mathrm{Cu}-\mathrm{W}$ nanocomposite, Mater. Des. 46 (2013) 16-25. https://doi.org/10.1016/j.matdes.2012.09.055

[7] F.A. Costa, A.G.P. Silva, U.U. Gomes. The influence of the dispersion technique on the characteristics of the $\mathrm{W}-\mathrm{Cu}$ powders and on the sintering behavior, Powder Technol. 134 (2003) 123-132. https://doi.org/10.1016/S0032-5910(03)00123-2

[8] M.H. Maneshian, A. Simchi, Solid state and liquid phase sintering of mechanically activated W-20wt.\% $\mathrm{Cu}$ powder mixture, J. Alloys Compd. 463 (2008) 153-159. https://doi.org/10.1016/j.jallcom.2007.08.080

[9] J.L. Johnson, J.J. Brezovsky, R.M. German, Effects of tungsten particle size and copper content on densification of liquid-phase-sintered W-Cu, Metall Mater Trans A. 36A (2005) 2807-2814. https://doi.org/10.1007/s11661-005-0277-y

[10] J.L. Johnson, J.J. Brezovsky, R.M. German, Effect of liquid content on distortion and rearrangement densification of liquid-phase-sintered W-Cu, Metall Mater Trans A. 36A (2005) 1557-1565. https://doi.org/10.1007/s11661-005-0247-4

[11] X. Wei, D. Yu, Z. Sun, et al., Arc characteristics and microstructure evolution of W/Cu contacts during the vacuum breakdown, Vacuum 107 (2014) 83-89. https://doi.org/10.1016/j.vacuum.2014.04.005

[12] A.K. Bhalla, J.D. Williams, A Comparative Assessment of Explosive and Other Methods of Compaction in the Production of Tungsten-Copper Composites, Powder Metal. 1 (1976) 3137. https://doi.org/10.1179/pom.1976.19.1.31

[13] J. Cheng, P. Song, Fabrication and characterization of $\mathrm{W}-15 \mathrm{Cu}$ composite powders by a novel mechano-chemical process, Mater. Sci. Eng. A. 488 (2008) 453-457. https://doi.org/10.1016/j.msea.2007.11.022

[14] S.H. Hong, B.K. Kim, Fabrication of W-20 wt \% Cu composite nanopowder and sintered alloy with high thermal conductivity, Mater. Lett. 57 (2003) 2761-2767. https://doi.org/10.1016/S0167-577X(03)00071-5 
[15] Y. Li, X. Qu, Z.S. Zheng, et al., Properties of W-Cu composite powder produced by a thermo-mechanical method, Int. J. Refract. Metal. Hard Mater. 21 (2003) 259-264. https://doi.org/10.1016/j.ijrmhm.2003.08.001

[16] L. Wan, J. Cheng, P. Song, et al., Synthesis and characterization of W-Cu nanopowders by a wet-chemical method, Int. J. Refract. Metal. Hard Mater. 29 (2011) 429-434. https://doi.org/10.1016/j.ijrmhm.2011.01.006

[17] X. Shi, H. Yang, S. Wang, et al., Characterization of W-20Cu ultrafine composite powder prepared by spray drying and calcining-continuous reduction technology, Mater. Chem. Phys. 104 (2007) 235-239. https://doi.org/10.1016/j.matchemphys.2007.03.032

[18] E.L. Courtright, A review of fundamental coating issues for high temperature composites, Surf. Coat. Technol. 68-69 (1994) 116-125. https://doi.org/10.1016/0257-8972(94)90148-1

[19] X.C. Zhang, B.S. Xu, H.D. Wang, et al, Effects of compositional gradient and thickness of coating on the residual stresses within the gradedcoating, Mater. Des. 28(4) (2007) 11921197. https://doi.org/10.1016/j.matdes.2006.01.012

[20] A. Polat, O. Sarikaya, E. Celik, Effects of porosity on thermal loadings of functionally graded $\mathrm{Y}_{2} \mathrm{O}_{3}-\mathrm{ZrO}_{2} / \mathrm{NiCoCrAlY}$ coatings, Mater. Des. 23(7) (2003) 641-644.

[21]J.J. Sobczak, L. Drenchev, Metallic Functionally Graded Materials: A Specific Class of Advanced Composites, Journal of Materials Science \& Technology, Volume 29, Issue 4, April (2013) 297-316.

[22] H.P.Yuan, L.G. Li, Q. Shen, et al, In situ synthesis and sintering of $\mathrm{ZrB}_{2}$ porous ceramics by the spark plasma sintering-reactive synthesis (SPS-RS) method. Int J Refract Met Hard Mater. 34 (2012) 413-417. https://doi.org/10.1016/j.ijrmhm.2012.01.007

[23] A. Teber, F. Schoenstein, F. Têtard, et al, The effect of Ti substitution by Zr on the microstructure and mechanical properties of the cermet $\mathrm{Ti}_{1}{ }_{-\mathrm{x}} \mathrm{Zr}_{\mathrm{x}} \mathrm{C}$ sintered by SPS. Int $\mathrm{J}$ Refract Met Hard Mater. 31 (2012) 64-70. https://doi.org/10.1016/j.ijrmhm.2011.06.013

[24] J.M. Lee, J.H. Kim, S.H. Kang. Advanced W-HfC cermet using in-situ powder and spark $\begin{array}{llllll}\text { plasma sintering. J Alloys } & \text { Compd. } & 552 & \text { (2013) }\end{array}$ https://doi.org/10.1016/j.jallcom.2012.09.116

[25] P. Feng, Y.H. He, Y.F. Xiao, et al., Effect of VC addition on sinterability and microstructure of ultrafine Ti(C, N)-based cermets in spark plasma sintering. J Alloys Compd. 460 (2008) 453-459. https://doi.org/10.1016/j.jallcom.2007.05.091

[26] L. Ding, D.P. Xiang, Y.Y. Li, et al., Effects of sintering temperature on fine-grained tungsten heavy alloy produced by high-energy ball milling assisted spark plasma sintering. Int $\mathrm{J}$ Refract Met Hard Mater. 33 (2012) 65-69. https://doi.org/10.1016/j.ijrmhm.2012.02.017

[27] A. Teber, F. Schoenstein, F. Têtard, et al., Effect of SPS process sintering on the microstructure and mechanical properties of nanocrystalline TiC for tools application. Int J Refract Met Hard Mater. 31 (2012) 64-70. https://doi.org/10.1016/j.ijrmhm.2011.06.013

[28] Z.H. Qiao, J. Räthel, L.M. Berger, et al., Investigation of binderless WC-TiC- $\mathrm{Cr}_{3} \mathrm{C}_{2}$ hard materials prepared by spark plasma sintering (SPS). Int J Refract Met Hard Mater. 38 (2013) 7-14. https://doi.org/10.1016/j.ijrmhm.2012.12.002 
[29] C.F. Hu, Y. Sakka, H. Tanaka, et al., Synthesis, microstructure and mechanical properties of (Zr, Ti)B2-(Zr, Ti)N composites prepared by spark plasma sintering. J Alloys Compd. 494 (2010) 266-270. https://doi.org/10.1016/j.jallcom.2010.01.006

[30] M. Eriksson, M. Radwan, Z.J. Shen, Spark plasma sintering of WC, cemented carbide and functional graded materials. Int J Refract Met Hard Mater. 36 (2013) 31-37. https://doi.org/10.1016/j.ijrmhm.2012.03.007

[31] H.B. Feng, Q.C. Meng, Y. Zhou, et al., Spark plasma sintering of functionally graded material in the $\mathrm{Ti}-\mathrm{TiB}_{2}-\mathrm{B}$ system. Mater Sci Eng. A. 397 (2005) 92-97. https://doi.org/10.1016/j.msea.2005.02.003

[32] X.L. Shi, H. Yang, S. Wang, Spark plasma sintering of $\mathrm{W}-15 \mathrm{Cu}$ alloy from ultrafine composite powder prepared by spray drying and calcining-continuous reduction technology, Mater Charact. 60 (2009) 133-137. https://doi.org/10.1016/j.matchar.2008.07.012

[33] X. Tang, H. Zhang, D. Du, et al., Fabrication of W- Cu functionally graded material by spark plasma sintering method, Int. Journal of Refractory Metals and Hard Materials, 42 (2014) 193-199. https://doi.org/10.1016/j.ijrmhm.2013.09.005

[34] Q. Zhang, S. Liang, L. Zhuo, Fabrication and properties of the $\mathrm{W}-30 \mathrm{wt} \% \mathrm{Cu}$ gradient composite with W@WC core-shell structure, Journal of Alloys and Compounds, 708 (2017) 796-803. https://doi.org/10.1016/j.jallcom.2017.03.064

[35] Q. Zhang, S.H. Liang, B.Q. Hou, et al., The effect of submicron-sized initial tungsten powders on microstructure and properties of infiltrated $\mathrm{W}-25 \mathrm{wt} \% \mathrm{Cu}$ alloys, Int. J. Refract. Met. Hard Mater. 59 (2016) 87-92. https://doi.org/10.1016/j.ijrmhm.2016.05.014 